\title{
MICROPROPAGACIÓN DE Tectona grandis L. f. A PARTIR DE MERISTEMOS PREEXISTENTES
}

\section{Tectona grandis L. f. MICROPROPAGATION FROM PREEXISTING MERISTEMS}

\author{
Janer Polo Santos ${ }^{1}$, Isidro Suarez Padrón², Kellen Cristina Gatti ${ }^{3}$ \\ Recibido para publicación: Abril 11 de 2013 - Aceptado para publicación: Diciembre 06 de 2013
}

\begin{abstract}
RESUMEN
La teca (Tectona grandis) es una especie forestal tropical introducida de la India, que por sus cualidades de madera y rápido crecimiento ha sido muy sembrada en Colombia; sin embargo, los procesos de producción masiva de material clonal para siembra siguen siendo una limitante. La propagación in vitro permite propagar clonalmente árboles seleccionados por sus características fenotípicas y alto rendimiento de la madera, incrementando la tasa de multiplicación y manteniendo un alto nivel de sanidad y estabilidad genética. En el presente estudio se evaluó el efecto de diferentes niveles de bencilaminopurina (0.0, 0.25, 0.5, 0.75 y 1.0 $\mathrm{mg} \mathrm{L}^{-1}$ ), en medio semisólido de MS, sobre la micropropagación de explantes con meristemos preexistentes provenientes de árboles adultos de teca. Los tratamientos fueron distribuidos utilizando un DCA, con 20 repeticiones por cada tratamiento y los cultivos mantenidos a $20^{\circ} \mathrm{C}$ con 12 horas de luz. La supervivencia de las plantas micropropagadas trasplantadas en turba o arena fue determinada bajo condiciones de casa malla. El ANOVA mostró que la presencia de BAP en el medio incrementa el número de nuevos brotes. La adición de auxinas es necesaria y suficiente para el enraizamiento in vitro de tallos micropropagados de teca, a la vez que incrementa su nivel en forma proporcional a la dosis de AIB. Las plantas tuvieron porcentajes de supervivencia superiores al $90 \%$ en ambos sustratos.
\end{abstract}

Palabras clave: Teca, propagación de tallos, in vitro.

\begin{abstract}
Teak (Tectona grandis) is a tropical forest tree introduced from India and highly appreciated in Colombia due to rapid growth and wood quality. However, massive production of clonal planting material is still a limiting factor. In vitro propagation allows clonally propagate superior adult plants with higher multiplication rates,

Tngeniero Agrónomo, MSc. Biotecnología, Investigador Asociado, Facultad de Ciencias Agrícolas, Universidad de Córdoba, Carrera 6 No. 76-103. Montería - Córdoba, Colombia. jpolo@fca.edu.co

${ }^{2}$ PhD., Docente Investigador, Facultad de Cien+cias Agrícolas, Universidad de Córdoba. Universidad de Córdoba, Carrera 6 No. $76-103$. Montería - Córdoba, Colombia. isidrosuarez@hotmail.com

${ }^{3}$ MSc., Docente asociada, Universidad Federal de Viçosa. Viçosa, Minas Gerais, Brasil. kellencristinag@yahoo.com.br
\end{abstract}


genetic stability and sanity. In the present research the effect of different BAP levels $(0.0,0.25,0.5,0.75$ and 1.0 $\mathrm{mg} \mathrm{L}^{-1}$ ), supplied on MS semisolid medium, on multiplication of explants with pre-existing meristem isolated from adult plants was evaluated. Treatments were distributed with a CRD and te crops maintained at $25^{\circ} \mathrm{C}$ with 12-hour photoperiod. Plant survival after transferring on sand or peat was also evaluated under shade house conditions. ANOVA showed that BAP supply increased shoot multiplication. The addition of auxin is necessary and sufficient for in vitro rooting of micropropagated shoots of teak, while its level increases in proportion to the dose of AIB. Plants had higher survival to $90 \%$ in both substrates.

Key words: Teak, shoot multiplication, in vitro.

\section{INTRODUCCIÓN}

La demanda de productos forestales seguirá creciendo a medida que aumente la población y los ingresos mundiales. Las proyecciones más recientes realizadas por la FAO estiman que para el 2030, el consumo global de madera en rollo industrial aumentará un $60 \%$ respecto a los niveles actuales, hasta alcanzar el orden de 2400 millones de $\mathrm{m}^{3}$. También es probable que se produzcan aumentos importantes en el consumo de productos de papel y cartón (FAO 2002).

La teca (Tectona grandis) es una especie forestal originaria del Sudeste de Asia, cuya madera es una de las más valiosas y mejor conocidas en el mundo. La FAO reporta que el área de las plantaciones de teca en el año 2009 en los principales países donde se cultiva; varía de un mínimo de alrededor de 2,3 a un máximo de 6,4 millones de hectáreas, pero tan solo el 3,4\% se encuentran ubicadas en Centro y Sur América. La mayoría de las plantaciones en Latinoamérica han sido establecidas por inversionistas particulares motivados por los altos precios que oscilan entre los US $\$ 300$ y US $\$ 1650$ el metro cúbico de trozas de aserrío (CATIE 2003; FAO 2009).

El programa de cadenas productivas forestales, tiene por objeto establecer una base forestal de 1.5 millones de hectáreas durante el período 2000 - 2025 (CONPES 2003). Dentro de las recomendaciones señaladas por el CONPES 3237 de 2003, se incluyen los planes de zonificación para plantaciones forestales, ampliación de la oferta forestal productiva, manejo y aprovechamiento sostenible de bosques naturales, conformación y modernización de empresas forestales y generación de condiciones para la exportación de bienes y servicios. Sin embargo, los logros alcanzados hasta el momento son limitados en materia de ampliación de oferta forestal, lo cual puede deberse en parte al déficit en cantidad y calidad de los materiales de siembra, además de limitaciones de tipo técnico, las cuales están relacionadas con las características inherentes a la propagación de especies forestales por métodos convencionales y baja oferta tecnológica (MINAMBIENTE 2001).

Colombia cuenta con un área aproximada de 25 millones de hectáreas con aptitud forestal, mientras que en el núcleo forestal del Departamento de Córdoba se han identificado aproximadamente 900.000 ha, con suelos de mediana a alta fertilidad, susceptibles de ser aprovechadas forestalmente. En el acuerdo de competitividad firmado en el año 2010, se estableció una meta de siembra de 100.000 ha 
con miras a abastecer el mercado regional y exportar productos elaborados en un plazo de 15 años. Sin embargo, a pesar del potencial de producción y oportunidades de mercado, existen limitantes relacionadas con la escasez de propágulos y disponibilidad de tecnologías para escalar la producción de material de siembra a partir de genotipos seleccionados que permita el establecimiento de plantaciones dirigidas a la silvicultura clonal con altos niveles de productividad (Murillo et al. 2011; Bose y Saigal 2004; Gatti et al. 2012).

En Córdoba existe una superficie de cultivos forestales de especies nativas e introducidas de 15.000 ha aproximadamente; un alto porcentaje de esta área se está sembrando y se espera sembrar con especies comerciales introducidas como Teca (Tectona grandis L.), Melina (Gmelina arborea Roxb) y Acacia (Acacia mangium Willd) de alta calidad de la madera y demanda en el mercado internacional. En teca, el áreas más significativa de bosque plantado se encuentran en la Hacienda "El Páramo" con 1.600 ha sembradas, las cuales corresponden al $6,72 \%$ del área total del municipio, de los cuales el 0,72\% corresponde a bosque secundario y 3,32\% a plantaciones para aprovechamiento y uso industrial. El volumen de madera movilizada en Córdoba en el año 2001 fue de 19.439,40 m³ de las cuales 13.630,50 $\mathrm{m}^{3}$ fueron sin transformar, de este valor el $86,08 \%$ correspondió a la especie teca destinada a la exportación (Cadena Forestal de Córdoba 2006).

La micropropagación in vitro de plantas forestales, es una de las herramientas que permite propagar árboles seleccionados por sus características fenotípicas como: altura, rectitud de fuste, copa y alto rendimiento de madera.
Además, esta técnica permitirá incrementar la tasa de multiplicación que por la vía sexual no se ha logrado. Otras de las ventajas es que puede mantener un alto margen de sanidad y estabilidad genética del material propagado por esta vía.

Una de las ventajas de la micropropagación es que brinda la posibilidad de clonar árboles adultos de gran valor comercial, conservando la uniformidad genética y reduciendo los riesgos fitosanitarias, incluso para satisfacer la creciente demanda de material de siembra para mercados internacionales.

En teca, la micropropagación de plantas fue reportada por primera vez en la India a finales de los años setenta, desde entonces, diversos trabajos se han realizado con el fin de mejorar las condiciones de cultivo in vitro y aumentar las tasas de multiplicación y de recuperación de plantas (Ramos 2000; Tiwari et al. 2002; Daquinta et al. 2003; Castro et al. 2002; Abdelnour y Muñoz 2005; Mendoza de Gyves et al. 2007; Cruz 2004).

Estos trabajos muestran la fuente de selección de los explantes provenientes de plantas adultas y brotes de estacas enraizadas, estrategias para la inducción del rejuvenecimiento del tejido adulto, las condiciones de preacondicionamiento y asepsia, finalmente las condiciones de medios de cultivos y reguladores de crecimiento utilizado para el establecimiento y multiplicación de brotes emitidos de teca, así mismos como el enraizamiento y la aclimatización ex vitro, resultados que permitieron comparar los resultados del presente trabajo.

En el presente trabajo se buscó establecer un protocolo de propagación rápida para árboles plus de teca, a través de explantes con meristemos 
preexistentes, como alternativa tecnológica para la producción de material vegetal para cultivos comerciales silvícolas en el departamento de Córdoba.

\section{MATERIALES Y MÉTODOS}

\section{Material vegetal}

Estacas de aproximadamente $10 \mathrm{~cm}$ de longitud fueron aisladas del tercio superior de diferentes árboles adultos (>10 años), plantados en campos de la empresa 3F Kanguroid (Tierralta - Córdoba, $8^{\circ} 48^{\prime} \mathrm{LN}$ y $\left.75^{\circ} 52^{\prime} \mathrm{LW}\right)$; posteriormente establecidas en sustrato (1:1 suelo:cascarilla de arroz) bajo condiciones controladas en un umbráculo con una cubierta de polisombra del $50 \%$ de cobertura, temperatura promedio de $28{ }^{\circ} \mathrm{C}$, humedad relativa del $80 \%$ y aplicaciones de aspersiones foliares con benzimidazol (2 g $\left.\mathrm{L}^{-1}\right)$ cada dos semanas. Los brotes emergentes fueron repetidamente aislados y enraizados con el fin de revigorizarlos durante cuatro ciclos consecutivos.

\section{Establecimiento in vitro y multiplicación de propágulo}

Los explantes consistieron de segmentos nodales (2-3 cm longitud) con dos yemas axilares aislados a partir de las estacas enraizadas, los cuales fueron lavados superficialmente con agua, detergente, Tween $20 \AA$ y oxicloruro de cobre $\left(2 \mathrm{~g} \mathrm{~L}^{-1)}\right.$ y posteriormente, fueron sumergidos por 15 minutos en una solución de $\mathrm{CaOCl}\left(8 \mathrm{~g} \mathrm{~L}^{-1}\right)$, enjuagados tres veces con agua destilada estéril y finalmente sumergidos en benzimidazol $\left(3 \mathrm{~g} \mathrm{~L}^{-1}\right)$ y cefalexina $\left(2 \mathrm{mg} \mathrm{L}^{-1}\right)$ por 20 minutos (Castro et al. 2009).

El establecimiento de los explantes se realizó en medio de establecimiento (ME) MS (Murashige y Skoog 1962) adicionado con (en $\mathrm{mg} \mathrm{L}^{-1}$ ) benzilaminopurina (BAP) $(0,5)$ sacarosa (30.000), tiamina $(2,0)$, myo-inositol (100), y TC agar (Sigma®) (7.000). El pH del medio fue ajustado a 5,7-5,8 y posteriormente esterilizado en autoclave durante 15 minutos a $120^{\circ} \mathrm{C}$ y $1,1 \mathrm{Kg} \mathrm{cm}^{-2}$. Los medios esterilizados fueron distribuidos en porciones de $15 \mathrm{~mL}$ de medio en frascos de compota; se estableció un explante por cada recipiente, el cual fue cubierto con dos capas de papel aluminio y sellado con Parafilm®. Los cultivos fueron mantenidos a $28{ }^{\circ} \mathrm{C}$, en completa oscuridad por dos semanas y posteriormente transferidos a 12 horas de fotoperiodo con lámparas de luz blanca $\left(12 \mathrm{~mol} \mathrm{~m} 2 \mathrm{~s}^{-2}\right)$.

Por otra parte, segmentos de tallo con dos nudos procedentes de las plantas establecidas in vitro por un tiempo total de seis meses $y$ cultivadas durante cuatro semanas en el ME fueron transferidos a medios de cultivo MS ( $50 \%$ de la concentración de sales), adicionado con diferentes cantidades de BAP $(0,0 ; 0,25$; 0,$5 ; 0,75$ y $1,0 \mathrm{mg} \mathrm{L}^{-1}$ ) y suplido con sacarosa (30.000), agar (7.000), tiamina (1), y myoinositol (100). Los cultivos fueron almacenados a $28{ }^{\circ} \mathrm{C}$ de temperatura, en completa oscuridad por dos semanas y posteriormente transferidos a condiciones de 12 horas de fotoperiodo suministradas por lámparas de luz blanca fluorescente (12 mol m2 s $\left.\mathrm{s}^{-2}\right)$. Los tratamientos se distribuyeron con un diseño completamente al azar con 20 repeticiones por tratamiento para un total de 100 unidades experimentales. A los 30 días de cultivo se evaluó el número de nuevos brotes, número de nudos, número de hojas, la formación de callo y la presencia de cultivos vitrificados. Los datos fueron 
analizados con ANOVA y los promedios separados con la prueba de separación de Duncan $(\alpha=0.05)$.

Enraizamiento in vitro. Para el enraizamiento in vitro, se emplearon tallos de 1,5 $\pm 0,5 \mathrm{~cm}$ dos meristemos axilares; los cuales se establecieron en un medio MS, suplido con diferentes cantidades de AIB $(0,0 ; 0,2 ; 0,6 ; 1,0$ y $1,4 \mathrm{mg}$ $\left.\mathrm{L}^{-1}\right)$ y adicionado con sacarosa (30.000), agar (7.000), tiamina (2), myo-inositol (100). Los cultivos se almacenaron a una temperatura de $27 \pm 2^{\circ} \mathrm{C}$ y 12 horas de fotoperíodo. A los 30 días se evaluaron, número promedio de raíces emitidas por brote y longitud promedio de la raíz en el medio de cultivo.

\section{Adaptación ex vitro}

Brotes micropropagados (3,0 cm de longitud), con dos a tres pares de hojas extendidas, fueron basalmente inmersos durante tres minutos en una solución de ácido indolbutírico (AIB) (5.000 $\left.\mathrm{mgL}^{-1}\right)$ y seguidamente plantados en bandejas de 42 unidades alveolares conteniendo turba o arena cuarzítica, con una cubierta plástica transparente. Las bandejas fueron colocadas utilizando un diseño de bloques al azar con cuatro repeticiones (cuatro bandejas para cada tratamiento) en un umbráculo con una polisombra del $50 \%$ de luminosidad, temperatura promedio de $28{ }^{\circ} \mathrm{C}$, humedad relativa de $80 \%$ y riego automatizado por microaspersión con una frecuencia de 30 segundos cada dos horas. A los 30 días se registró en número de plantas sobrevivientes en cada tipo de sustrato y se calculó el porcentaje de supervivencia.

\section{RESULTADOS Y DISCUSIÓN}

\section{Establecimiento in vitro y multiplicación de propágulo \\ El crecimiento de los nuevos brotes a partir de los explantes ocurrió a partir de los meristemos pre-existentes (yemas) presentes en el propágulo original observándose el crecimiento de tallos y hojas después de 15 días del establecimiento in vitro (Figura 1a).}
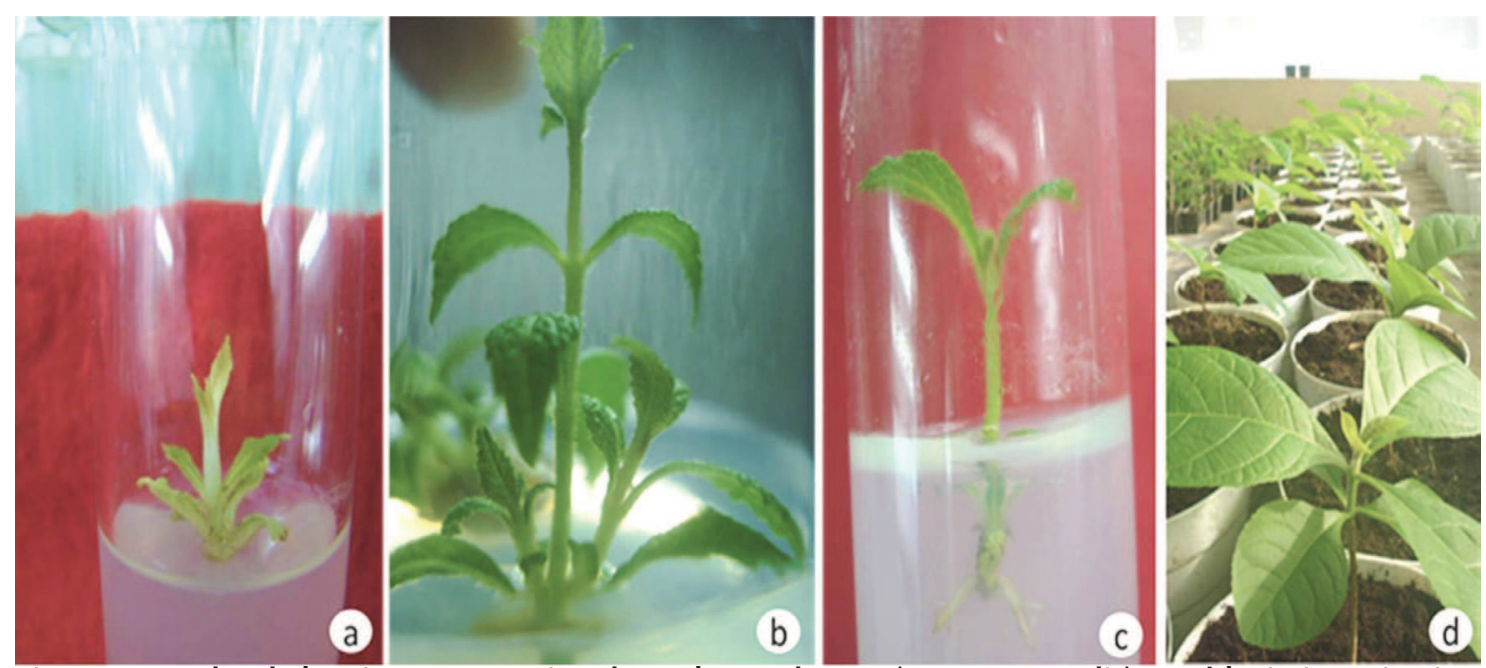

Figura 1. Estados de la micropropagación de explantes de teca (Tectona grandis): Establecimiento in vitro (a), multiplicación de propágulo (b), enraizamiento in vitro (c) y aclimatación de plantas a condiciones ex vitro (d). 
El análisis de varianza permitió detectar la presencia de diferencias estadísticamente significativas $(\mathrm{Pr}=0.021)$ con respecto al número de nuevos brotes producidos por explante como efecto de la adición de diferentes dosis de BAP en el medio de cultivo.

La prueba de comparación de medias demostró que la producción de nuevos brotes en los explantes cultivados en presencia de $\geq 0.5 \mathrm{mgL}^{-}$ 1 de BAP fue significativamente superior al tratamiento control (Tabla 1).

Esta respuesta coincide con la reportada en estudios realizados en esta $y$ otras especies vegetales donde se evidencia que la adición exógena de citocininas promueve el rompimiento de la dominancia apical y consecuentemente, una activación del crecimiento de los meristemos axilares presentes en los explantes cultivados in vitro, propiciando un aumento en la tasa de multiplicación por la formación de nuevos brotes. (Mendoza de Gyves et al. 2007). Una de las posibles explicaciones a esta respuesta es la producción de un desequilibrio en la relación endógena entre las concentraciones de auxinas y citocininas, lo que se manifiesta en la liberación del crecimiento de los brotes axilares en una forma repetitiva (Mendoza de
Gyves et al. 2007; Pedroza y Bejarano 2008; Akram y Aftab 2009).

Los datos reportados en el presente estudio muestran similitud con estudios publicados por otros investigadores para esta misma especie: Castro et al. (2002), observaron la mayor tasa de multiplicación (2,5 brotes por explante) y calidad de brotes cuando adicionaron el medio de cultivo MS semisólido con $0.5 \mathrm{mg}$ $\mathrm{I}^{-1}$ de BAP. Cruz (2004) obtuvo un promedio de dos nuevos brotes por cada propágulo al cultivar los explantes en un medio MS con una combinación de 1,0 $\mathrm{mgL}^{-1}$ BAP con 0,5 $\mathrm{mgL}^{-}$ 1 de kinetina, observándose poca diferencia entre las combinaciones de citocininas con su uso de forma individual reportado en otros estudios. Por su parte, Abdelnour y Muñoz (2005) utilizando dosis entre 1,0 y $2,0 \mathrm{mgL}^{-1} \mathrm{de}$ BAP aumentaron la tasa de multiplicación de explantes aislados de plántulas juveniles entre 4,0 y 4,6 nuevos brotes, respectivamente.

Mendoza de Gyves et al. (2007) reportaron tasas de multiplicación similares a las del estudio anteriormente referenciado utilizando un medio MS con $50 \%$ de reducción en la concentración de $\mathrm{NH}_{4} \mathrm{NO}_{3}$, y adicionado con $1,5 \mathrm{mgL}^{-1} \mathrm{BAP}$ en combinación con $0,01 \mathrm{mgL}^{-1}$ AIA y $0,1 \mathrm{mgL}^{-1}$ de $\mathrm{AG}_{3}$.

Tabla 1. Efecto de diferentes niveles de BAP sobre el número de brotes, nudos y hojas producidos a partir de explantes con meristemos pre-existentes de teca (Tectona grandis).

\begin{tabular}{cccc}
\hline $\begin{array}{c}\text { BAP } \\
\left(\mathrm{mg} \mathrm{L}^{-1}\right)\end{array}$ & $\begin{array}{c}\text { Número } \\
\text { de } \\
\text { nuevos } \\
\text { brotes }\end{array}$ & $\begin{array}{c}\text { Número de } \\
\text { nudos por } \\
\text { brote }\end{array}$ & $\begin{array}{c}\text { Número de } \\
\text { hojas }\end{array}$ \\
\hline 1,00 & $2,6^{\mathrm{a}}$ & $5,6^{\mathrm{a}}$ & $12,4^{\mathrm{a}}$ \\
0,75 & $2,2^{\mathrm{a}}$ & $4,0^{\mathrm{a}}$ & $8,60^{\mathrm{a}}$ \\
0,50 & $2,4^{\mathrm{a}}$ & $5,8^{\mathrm{a}}$ & $12,8^{\mathrm{a}}$ \\
0,25 & $2,0^{\mathrm{ab}}$ & $4,8^{\mathrm{a}}$ & $9,60^{\mathrm{a}}$ \\
0,00 & $1,2^{\mathrm{b}}$ & $4,4^{\mathrm{a}}$ & $9,00^{\mathrm{a}}$ \\
\hline
\end{tabular}

Medias con la misma letra no son significativamente diferentes de acuerdo con Duncan ( $\alpha=0.05)$ 
El análisis de varianza realizado no permitió observar diferencias estadísticas significativas entre los datos colectados para las variables número de nudos por brote $(\operatorname{Pr}=0.32)$ y número de hojas por brote $(\operatorname{Pr}=0.08)$ como consecuencia del efecto de los tratamientos aplicados (Tabla 1).

Los resultados de estudios previos relacionados con el efecto de BAP sobre el incremento del número de nudos y hojas por nuevos brotes de teca en condiciones in vitro, y otras especies, no muestran una tendencia uniforme en la respuesta de los mismos con respecto a estas variables. Ramos (2000) encontró que el número de nudos y hojas en los brotes aumentó a medida que disminuyeron los niveles de citocininas en el medio, mientras que, de forma inversa, otros estudios reportaron que a medida que se aumentó la concentración de BAP en el medio, se observó una disminución de la longitud de los brotes y con ello una reducción del número de nudos y hojas (Pedroza y Tupaz 2008; Bejarano 2008); probablemente, las bajas concentraciones de citocininas utilizadas en el presente estudio contribuyó a no observar esta respuesta.

La hiperhidricidad es un desorden morfofisiológico caracterizado por una exagerada suculencia de órganos, apariencia vítrea de las plantas con bajo contenido de clorofila y almacenamiento anormalmente alto de agua en los tejidos que demeritan la calidad de los brotes (Debergh y Maene 1981; Gaspar 1991; Franck et al. 2004; Castro et al. 2009).

Aunque la adición de citocininas en el medio se ha relacionado con la incidencia de vitrificación en la micropropagación de muchas especies, incluyendo leñosas perennes, esta parece estar asociada con el uso de concentraciones relativamente altas de este tipo de reguladores de crecimiento (Ivanova y van Staden 2009; Moncalean et al. 2005).

En el desarrollo del presente trabajo no se apreciaron condiciones de hiperhidricidad o vitrificación en los órganos de los brotes micropropagados, lo cual, con base en lo reportado en estudios y revisiones anteriores, pudo ser el resultado de las bajas concentraciones de BAP $\left(\leq 1,0 \mathrm{mg} \mathrm{L}^{-1}\right)$ utilizadas para promover la proliferación de brotes axilares a partir de los explantes cultivados, como tampoco se registró formación alguna de callo.

\section{Enraizamiento in vitro}

Los estudios relacionados con el efecto de auxinas en el enraizamiento de teca no han

Tabla 2. Promedio del efecto de los tratamientos sobre la variable número y longitud de raíces desarrolladas a nivel in vitro en teca.

\begin{tabular}{ccc}
\hline Tratamiento & $\begin{array}{c}\text { Número de } \\
\text { raíces }\end{array}$ & Longitud raíz (cm) \\
\hline $1,4 \mathrm{mgl}^{-1}$ & $1,3 \mathrm{a}$ & $0,8^{\mathrm{a}}$ \\
$1,0 \mathrm{mgl}^{-1}$ & $1,1 \mathrm{ab}$ & $1,0^{\mathrm{a}}$ \\
$0,6 \mathrm{mgl}^{-1}$ & $0,9 \mathrm{cb}$ & $0,7^{\mathrm{a}}$ \\
$0,2 \mathrm{mgl}^{-1}$ & $0,8 \mathrm{c}$ & $0,9^{\mathrm{a}}$ \\
$0,0 \mathrm{mgl}^{-1}$ & $0,7 \mathrm{c}$ & $0,7^{\mathrm{a}}$ \\
\hline Medias con la misma letra no son significativamente diferentes de acuerdo con
\end{tabular}


mostrado resultados consistentes. Se ha observado que al aumentar las cantidades de $\mathrm{AIB}$ en el medio se incrementaron los porcentajes de enraizamiento (Husen y Pal 2003).

También se reporta que la teca tiende a enraizar espontáneamente dependiendo de los niveles endógenos del regulador de crecimiento, afirmando incluso que la presencia de altas concentraciones de AIB en el medio tienden a disminuir el porcentaje de enraizamiento y aumentan la formación de callos en la base de los tallos (Castro y Díaz 2009; Abdelnour y Muñoz 2005) reportaron la formación de raíces en $18 \%$ de los brotes sin adición de auxinas en el medio, valor semejante a lo obtenido con $0,2 \mathrm{mgL}^{-1}$ de AIB en este experimento.

Con relación a la longitud promedio de raíces, los análisis permitieron detectar que no se presentaron diferencias estadísticas ( $\mathrm{Pr}=0.35)$ por el efecto de los tratamientos evaluados, indicando que el tamaño de las raíces es independiente de la cantidad de auxina presente en el medio. No obstante, independientemente de su tamaño, las raíces formadas in vitro se caracterizan en su mayoría por ser fisiológicamente poco eficientes y funcionales debido a la fácil hidratación y nutrición de los tejidos a partir del medio de cultivo; adicionalmente, se ha observado que, anatómicamente, las conexiones vasculares entre el tallo y las raíces formadas in vitro son muy débiles, lo que propicia generalmente su rápido deterioro, necesitando que sean remplazadas rápidamente por nuevas formaciones radicales durante la fase de acondicionamiento ex vitro (Rogers y Smith 1992; Castro y Díaz 2009).

\section{Aclimatización de plántulas}

Las plantas trasplantadas y adaptadas a condiciones ex vitro mostraron una apariencia normal en crecimiento y forma de los órganos (Figura 1d). Los datos registrados mostraron que las plantas enraizaron en un $93,3 \%$ y $100 \%$ cuando fueron trasplantadas en turba y arena cuarzítica, respectivamente.

Estos resultados concuerdan con los reportados por Cruz (2004) quien observó un 94 y 100\% de enraizamiento de brotes micropropagados de teca al utilizar aplicaciones en forma de polvo de $1500 \mathrm{mg} \mathrm{Kg}^{-1} \mathrm{ANA}+1500 \mathrm{mg} \mathrm{Kg}^{-1}$ de AIB y $1000 \mathrm{mg} \mathrm{Kg}^{-1}$ de ANA+ $1000 \mathrm{mg} \mathrm{Kg}^{-1}$ de AIB respectivamente. Por su parte, Castro et al. (2002) reportaron los mayores porcentajes de enraizamiento (77\%) cuando emplearon la inmersión de los brotes en una solución de $4.000 \mathrm{mgL}^{-1}$ de AIB.

Los choques o inducciones hormonales están asociados con los niveles de competencia de las células presentes en las zonas tratadas; a mayor competencia las células tienen menores grados de determinación en sus funciones originales y pueden ser re-direccionadas con mayor facilidad a cumplir otras funciones; la presencia de auxinas, el grado de competencia celular y el tiempo de exposición son factores críticos para lograr la inducción radical en los explantes (Christianson y Warnik, 1985; Hartmann et al. 2002). Varios reportes evidencian la favorabilidad del uso de choques hormonales con reguladores de crecimiento tipo auxinas para incrementar los índices de recuperación de las plantas micropropagadas una vez transferidas a las condiciones ex vitro (Castro et al. 1999; Pedroza y Tupaz. 


\section{CONCLUSIONES}

La adición de BAP en el medio de cultivo incrementó de forma significativa la tasa de multiplicación de brotes de teca observándose los mayores promedios con dosis $\geq 0.5 \mathrm{mgL}^{-1}$ comparado con el tratamiento control.

El número de nudos por brote y número de hojas por brote no fueron afectadas por la adición de BAP en el medio de cultivo.

La adición de auxinas es necesaria y suficiente para el enraizamiento in vitro de tallos micropropagados de teca, a la vez que incrementa su nivel en forma proporcional a la dosis de AIB.

Es posible la aclimatización de teca logrando porcentajes de $93,3 \%$ y $100 \%$ de sobrevivencia de las plantas micropropagadas y trasplantadas a condiciones ex vitro en turba y arena cuarzítica respectivamente.

\section{AGRADECIMIENTOS}

Los autores expresan sus agradecimientos a La Universidad de Córdoba - División de Investigación, El Ministerio de Agricultura y Desarrollo Rural de Colombia, 3F-Kanguroid y FORCARIBE, por el apoyo para la realización de esta investigación.

\section{REFERENCIAS}

Abdelnour, A. y Muñoz, A. 2005. Micropropagación de teca (Tectona grandis L.f.). Kurú: Revista Forestal Mesoamericana 2(5). URL: http://www.tec-digital.itcr. ac.cr/servicios/ojs/index.php/kuru/article/ view/541/467 [Accedido: 03/21/2013]

Akram, M. and Aftab, F. 2009. An efficient method for clonal propagation and in vitro establishment of softwood shoots from epicormic buds of teak (Tectona grandis L.). Forest Science and Practice 11(2):105-110

Bose, S. y Saigal, S. 2004. Grandes planes para pequeñas empresas. Actualidad Forestal Tropical 12(1):16-17.

CADENA FORESTAL DE CÓRDOBA. 2006. Plan de Desarrollo Forestal Córdoba (PDFC), $p$ 130.

Castro, D., Díaz, J. y Linero, J. 2002. Propagación in vitro de árboles élite de teca (Tectona grandis L.). Revista Colombiana de Biotecnología 1:49-53.

Castro, D., Díaz, J. y Murillo, M. 1999. Estrategias de trabajo para la multiplicación clonal in vitro de árboles adultos de teca (Tectona grandis), melina (Gmelina arborea) y roble (Tabebuia rosea). Informe Final de Asesoría Técnica. Universidad Católica de Oriente, Rionegro, Colombia, p16-51.

Castro D. y Díaz, J. 2009. Micropropagación de árboles plus de teca (Tectona grandis). Memorias I Congreso Internacional del Cultivo de Teca. Quevedo-Los Ríos-Ecuador, p8.

CATIE. 2003. Semillas Forestales-PROSEFOR. Manual Técnico No. 30, Serie Técnica Turrialba, 36p.

CONPES. 2003. Política de estímulo a la reforestación comercial en Colombia: 2003- 
2006. Documento No. 3237.18 p.

Cruz, N. 2004. Micropropagación clonal in vitro de árboles seleccionados de Tectona grandis L. (Teca). URL: http://www.uteq. edu.ec/u_investigacion/biotecnologia/5.pdf. [Accedido: 03/04/2013].

Christianson, M. and Warnikm, D. 1985. Temporal requirement for phytohormone balance in the control of organogenesis in vitro. Developmental Biology 112:494.

Daquinta, M., Ramos, L., Rodríguez, R. y Escalona, M. 2003. Algunos elementos en la micropropagación de la teca. Biotecnología Vegetal 1:39-44

Debergh, P. and Maene, L. 1981. A scheme for commercial propagation of ornamental plants by tissue culture. Scentia Horticulturae 14:335-345.

FAO (Food and Agricultural Organization). 2009. The future of teak and the high-grade tropical hardwood sector: planted forests and trees. Working Paper FP/44E. URL: http://www. fao.org/forestry/site/10368/en/ [Accedido: 2013/02/21]

FAO. (Food and Agricultural Organization). 2002. Evaluación de los recursos forestalesmundiales 2000 - Informe principal. Estudio FAO: Montes No 140. Roma. URL: www.fao.org/forestry/fo/fra/main/index.jsp [Accedido: 2013/03/20]

Husen, A. and Pal, M. 2003. Clonal Propagation of Teak (Tectona grandis Linn. f.): Effect of IBA Application and Adventitious
Root Regeneration on Vertically Split Cuttings. Plant Physiology, Botany Division, Forest Research Institute, P.O. New Forest, Dehra Dun-248006, India.

Franck, T., Kevers, C., Gaspar, T., Dommes, J., Deby, C., Greimers, R., Serteyn D. and Deby, G. 2004. Hyperhydricity of Prunus avium shoots cultured on Gelrite: A controlled stress response. Plant Physiology and Biochemistry 42:519-527.

Gatti, K., Suárez, I., Espitia, M. y Tobar, D. 2012. Producción de Plántulas Forestales de Tectona grandis Linn F., Acacia mangium Willd y Gmelina arbórea Roxb. Universidad de Córdoba, Montería, 77p.

Gaspar, T., Penel, C., Hagege, D. and Greppin, H. 1991. Peroxidases in plant growth, differentiation, and developmental processes. En: Lobarzewski, J., Greppin, H., Hartmann, H., Kester, D., Davies, J. y Geneve, R. 2002. Plant Propagation, Principles and Practices. Prentice Hall Inc., Upper Saddle River (USA), p277-3323.

Ivanova, M. and van Staden, J. 2009. Nitrogen source, concentration, and $\mathrm{NH} 4+: \mathrm{NO} 3-$ ratio influence shoot regeneration and hyperhydricity in tissue cultured Aloe polyphylla Plant Cell Tissue and Organ Culture 99 (2):167-174 .

Mendoza de Gyves, J., Royani, I. and Rugini, E. 2007. Efficient method of micropropagation and in vitro rooting of teak (Tectona grandis L.) focusing on large-scale industrial plantations. Annals of Forest Sciences 64:73-78. 
Moncaleán, P., Alonso, P., Centeno, M., Cortizo, M., Rodriguez, A., Fernández B. and Ordás, R. 2005. Organogenic responses of Pinus pinea cotyledons to hormonal treatments: BA metabolism and cytokinin content. Tree Physiology 25:1-9

Murashige, T. and Skoog, F. 1962. A revised medium for rapid growth and bioassay with tobacco tissue culture. Physiologia Plantarum 15:473-497

Murillo, O., Espitia, M. y Castillo, C. 2011. Fuentes Semilleras para la Producción Forestal. Universidad de Córdoba, Montería, 77p.

Pedroza, J. y Bejarano, A. 2008. Propagación vegetativa in vitro de Puya santossi. Revista Colombiana de Biotecnología 10 (1): 36-48.
Pedroza, J. and Tupaz, W. 2008. Micropropagación de llex kunthiana \& Planchon (Aquifoliaceae), una especie de gran importancia en programas de revegetalización. Revista Colombiana de Biotecnología 10 (2):72-84.

Ramos, L. 2000. Algunos avances en la morfogénesis de la teca (Tectona grandis L.). Tesis M. Sc., Universidad Ciego de Avila, Cuba. 50pp.

Tiwari, S., Tiwari, K. and Siril, E. 2002. An improved micropropagation protocol for teak. Plant Cell, Tissue and Organ Culture 71(1):1-6. 